\title{
Increased blood cadmium levels were not associated with increased fracture risk but with increased total mortality in women: the Malmö Diet and Cancer Study
}

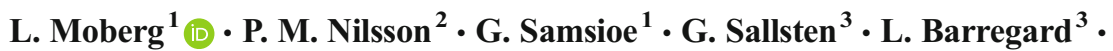 \\ G. Engström ${ }^{2} \cdot$ C. Borgfeldt ${ }^{1}$
}

Received: 6 July 2016 / Accepted: 10 April 2017 / Published online: 21 April 2017

(C) The Author(s) 2017. This article is an open access publication

\begin{abstract}
Summary This study aimed to investigate if high levels of blood cadmium at baseline were associated with increased fracture risk during follow-up in middle-aged women. No increased fracture risk was observed during follow-up, but women with higher levels of cadmium had an increased overall mortality.

Introduction Exposure to high levels of cadmium has been associated with an increased fracture risk. The aim was to investigate a perceived association between low levels of blood cadmium (B-Cd) at baseline and risk of first incident fracture.

Methods From the population-based Malmö Diet and Cancer Study Cardiovascular cohort, 2920 middle-aged women with available background questionnaire and B-Cd measurements were included. Women were divided into quartiles $(\mathrm{Q})$ according to their cadmium levels (Cd-Q1 $<0.18 \mu \mathrm{g} / \mathrm{L}$, Cd-Q2 0.18 $0.28 \mu \mathrm{g} / \mathrm{L}, \mathrm{Cd}-\mathrm{Q} 30.28-0.51 \mu \mathrm{g} / \mathrm{L}$, and Cd-Q4 $>0.51 \mu \mathrm{g} / \mathrm{L}$ ). National registries were analysed for prospective risk of fractures or death. Associations between B-Cd and fracture risk were assessed by survival analysis (Cox regression analysis). Results In total, 998 first incident fractures occurred in women during a follow-up lasting 20.2 years (median) (12.5-
\end{abstract}

L. Moberg

louise.moberg@med.lu.se

1 Department of Obstetrics and Gynaecology, Clinical Sciences, Lund University, Skåne University Hospital, SE-221 85 Lund, Sweden

2 Department of Internal Medicine, Clinical Sciences, Lund University, Skåne University Hospital, Malmö, Sweden

3 Department of Occupational and Environmental Medicine, Institute of Medicine, Sahlgrenska Academy, University of Gothenburg, Sahlgrenska University Hospital, Gothenburg, Sweden
21.2 years) (25th-75th percentile). Women in Cd-Q4 were more often current smokers than in Cd-Q1 78.4 vs. 3.3\% $(p<0.001)$ and the number of cigarettes smoked per day correlated with B-Cd $(r=0.49 ; p<0.001)$. The risk of fracture was not associated with baseline B-Cd in adjusted models. The hazard ratio (HR) Cd-Q4 vs. Cd-Q1 was 1.06 (95\% confidence interval (CI) 0.89-1.27). In the multivariate Cox regression, independent variables for increased fracture risk were history of gastric ulcer and increasing age, whereas increasing body mass index (BMI) lowered fracture risk. Overall mortality was significantly higher for women with high B-Cd, HR 2.06 (95\% CI 1.57-2.69).

Conclusions Higher blood levels of cadmium did not increase fracture risk in middle-aged women but reduced overall survival.

Keywords Cadmium · Diabetes mellitus · Fracture risk · Gastric ulcer $\cdot$ Mortality $\cdot$ Women

\section{Introduction}

Cadmium (Cd) is a naturally occurring element in the earth's crust and a widespread contaminant in soil from natural sources, cadmium-containing fertilisers, or deposition from industrial emissions. It accumulates in growing plants and is present in e.g. rice, cereals, potatoes and other food items consumed by humans [1]. Smoking is the second most common way to accumulate $\mathrm{Cd}$ in the body. Today, occupational exposure (e.g. at production of batteries, soldering, or cadmium plating) is rare.

Cadmium enters the body mainly through the lungs (in smokers) or via the gastrointestinal tract. It is accumulated in the kidneys and is eliminated at a very slow rate, with a half time of decades. Cadmium levels in blood and urine are used 
for monitoring exposure and body burden. The most well-known adverse effect is kidney damage, but cadmium has also been associated with detrimental impact on bone structure and an increased risk of osteoporosis and fracture [2-4]. A dose-response relation is still uncertain, and there are also studies observing no skeletal effects by increasing levels of cadmium [4]. Several previous studies in Sweden observed an increased risk of osteoporosis and/or fracture in individuals exposed to $\mathrm{Cd}$ environmentally [5-8]. One study from the southern part of Sweden found decreased bone mineral density (BMD) even by low levels of cadmium [9]. Cadmium is also a human carcinogen (International Agency for Research on Cancer (IARC) group 1) and has also been associated with an increased risk of cardiovascular disease [10].

The Malmö Diet and Cancer Study (MDCS) was primarily initiated to study the association between diet and risk of cancer. In the cardiovascular sub-cohort, several studies were performed on associations between $\mathrm{Cd}$ and atherosclerosis and cardiovascular disease [10-12]. In the present study, this subcohort was used to investigate the relationship between levels of $\mathrm{Cd}$ in blood at baseline and the risk of the first incident fracture during follow-up.

\section{Subjects and methods}

\section{Study population}

The MDCS was initiated in 1991 and was previously described in detail [13]. In short, all women and men born 1923-1945 and residing in the city of Malmö were invited to participate in the study. In addition, a random selection of subjects ( $n=6103)$ was invited in 1992-1994 to participate in the cardiovascular cohort (MDC-CV) to further include ultrasonography of the carotid artery and fasting blood sampling [14]. In the present analysis of the MDC-CV cohort, all women were included $(n=2920)$ that had results from the baseline questionnaire, physical examination, and blood cadmium (B-Cd) levels. Follow-up regarding vital status was available for participants until the 31 st of December 2013 and includes vital status at endpoint, i.e. alive, dead, or emigrated.

All participants provided written informed consent and the study was approved by the Lund University Ethics Committee (MDC LU 51-90) and for the cadmium sub-study (2009/633). The current study was also approved by the steering committee of the MDC study (2015-011). Data retrieval from the separate outpatient data registry covering the years 1992-2001 were granted by the Deputy Chief Health Officer (Region Skåne; decision number 236-16).

\section{Blood cadmium assessments}

Cadmium levels were analysed in erythrocytes and whole blood concentration was calculated using haematocrit (erythrocyte-Cd $\times$ haematocrit $/ 100$ ). An inductively coupled plasma mass spectrometry (Agilent 7700× ICP-MS, Agilent Technologies, Santa Clara, CA, USA) was used for cadmium erythrocyte concentrations [12]. Samples were analysed in three different rounds including two external quality control (QC) samples. The results were similar for all three rounds [12]. The limit of detection (LOD) was $0.02 \mu \mathrm{g} / \mathrm{L}$ and no sample was below that limit. Blood $\mathrm{Cd}$ concentrations were categorised into quartiles (Cd-quartile $1<0.18 \mu \mathrm{g} / \mathrm{L}, \mathrm{Cd}-$ quartile $20.18-0.28 \mu \mathrm{g} / \mathrm{L}$, Cd-quartile $30.28-0.51 \mu \mathrm{g} / \mathrm{L}$, and Cd-quartile $4>0.51 \mu \mathrm{g} / \mathrm{L}$ ).

\section{Measurement of covariates}

C-reactive protein (CRP) was analysed by a high-sensitive method from frozen plasma, collected at the baseline examination, with a Tina-quant CRP latex high-sensitivity assay (Roche Diagnostics, Basel, Switzerland) [15]. HbA1c, insulin, and whole blood glucose were analysed with standard procedures at the Department of Clinical Chemistry, Skåne University Hospital, Malmö [16]. HbA1c was measured by ion exchange chromatography and insulin was measured by radioimmunoassay in milli-international units per litre [16].

Smoking was self-reported and categorised as "regular smoker", "occasional smoker", "previous smoker", or "never smoker". In these analyses, regular smokers and occasional smokers were grouped as "current smokers". Alcohol intake was self-reported and grouped according to no alcohol intake during the last 30 days or more, current intake of $<15 \mathrm{~g} /$ day, and current intake of $>15 \mathrm{~g} /$ day of alcohol.

\section{Fracture outcome data}

Data for fracture and fracture code, according to the International Classification of Disease (ICD) 9 and 10, for first incident fractures during follow-up were collected using every individual's unique personal identification number up until the 31st of December 2013 from the National Patient Registry (Patientregistret) kept by the National Board of Health and Welfare (Socialstyrelsen). Only fractures occurring after individual inclusion in the study were included in the analyses. Fractures requiring hospitalisation are included for the entire nation since 1987, and fractures treated as outpatient in policlinic care are included since 2001. Outpatient data regarding fractures occurring between 1992 and 2001 were retrieved from the regional diagnosis registry.

Typically, osteoporotic fractures of the hip, distal radius, forearm, pelvis, distal femur, and humerus were also grouped into non-vertebral osteoporotic fracture for further analysis 
[17] excluding vertebral fractures as not all vertebral fractures are diagnosed [18]. In order not to underestimate nonvertebral osteoporotic fractures, all first non-vertebral osteoporotic fractures were included even if occurring after a nonosteoporotic first incident fracture.

The following ICD 9 codes were included in the search algorithm: $805,805 \mathrm{~A}, 805 \mathrm{C}, 805 \mathrm{E}, 805 \mathrm{~W}, 807,807 \mathrm{~A}, 808$, $808 \mathrm{~W}, 810,811,812 \mathrm{~A}, 812 \mathrm{C}, 812 \mathrm{E}, 813,813 \mathrm{C}, 813 \mathrm{E}, 814$, $815,816,820,820 \mathrm{~A}, 820 \mathrm{C}, 821,821 \mathrm{~A}, 821 \mathrm{C}, 822,823$, $823 \mathrm{~A}, 823 \mathrm{C}, 824,825,825 \mathrm{~A}, 826$, and 827.

The following ICD 10 codes were included in the search algorithm: M485, M843, S2200, S2220, S2230, S2240, S2290, S320, S3210, S3230, S3240, S3250, S3280, S420, S4210, S4220, S4230, S4240, S4270, S5200, S5210, S530, S5250, S5260, S5261, S5280, S6200, S6210, S6220, S6230, S6250, S6260, S6280, S7200, S7210, S7220, S7230, S8200, S8210, S8220, S8230, S8240, S8250, S8260, S8280, S8281, S8290, S9200, S9210, S9220, S9230, S9240, and S9250.

\section{Statistical analyses}

The distribution of continuous data was controlled by the Kolmogorov-Smirnov test. All parametric data are presented as means (standard deviation (SD)) and non-parametric data as medians (interquartile range (25th-75th quartile)). The Students' $t$ test, the Mann-Whitney $U$ test, and the independent Kruskal-Wallis test were used for comparing groups. Categorical data were analysed using the chi-square test. Cox proportional hazards regression was used to calculate hazard ratios (HR) and 95\% confidence intervals (CI).

Cox regression analyses were performed as univariate crude and multivariate adjusted for BMI, age, smoking status (never/previous/current smoker), self-reported diabetes mellitus, and gastric ulcer (verified by X-ray or gastroscopy).

All analyses were carried out using the IBM SPSS version 22.0 (IBM Corporation) apart from the competing risk analysis that was performed using Stata Statistical Software (STATA) ver. 12.1. (StataCorp). A $p$ value of $<0.05$ was considered statistically significant.

\section{Results}

In total, 998 women sustained a first incident fracture during follow-up. The number of non-vertebral osteoporotic fractures were 659 occurring either as a first incident non-vertebral osteoporotic fracture $(n=590)$ or subsequent to a previous non-osteoporotic first incident fracture $(n=69)$. The most common fractures were distal radius fracture $(n=294$ (29.5\%)), hip fracture $(n=199(19.9 \%))$, and upper humerus fracture $(n=89(8.9 \%))$ occurring either as a first incident fracture or as a non-vertebral osteoporotic fracture. Time to first fracture was $11.4(6.0-16.5)$ years for all women with a fracture, and no difference was noticed for women in Cd-Q4 compared to Cd-Q1 11.2 (6.9-16.8) vs. $11.6(6.2-16.3)$ years $(p=0.49)$. The number of any first incident fractures were not different for women in Cd-Q4 compared to Cd-Q1 243 $(33.3 \%)$ vs. 248 (34.0\%); $p=0.78$, but more women in CdQ4 had died at the end of follow-up compared to Cd-Q1 153 $(21.0 \%)$ vs. $82(11.2 \%) ; p<0.001)$. Median total follow-up time in the study from baseline inclusion to censored endpoint was 20.2 years (12.5-21.2 years).

Women in Cd-Q4 had a lower weight and BMI and a slightly lower age at menopause than women in Cd-Q1 (Table 1). Fewer women in Cd-Q4 were married or cohabiting, and more of them were current smokers and high consumers of alcohol (daily intake $>15 \mathrm{~g} /$ day) (Table 1). For current smokers, the number of smoked cigarettes/day $(n=686)$ correlated with B-Cd: Spearman's rank correlation coefficient $r=0.49(p<0.001)$. The median level of B-Cd (25th and 75th percentile) according to smoking status was $0.21(0.16-0.29) \mu \mathrm{g} / \mathrm{L}$ for never smokers, $0.25(0.18-0.35) \mu /$ $\mathrm{L}$ for previous smokers, and $0.92(0.56-1.41) \mu \mathrm{g} / \mathrm{L}$ for current smokers $(p<0.001)$.

The level of CRP was not different when comparing women in Cd-Q4 to Cd-Q1, but women in Cd-Q4 had higher CRP level than women in the combined group of Cd-Q1-3 $1.5(0.7-3.4) \mathrm{mg} / \mathrm{L}$ vs. $1.3(0.7-2.6) \mathrm{mg} / \mathrm{L}(p=0.002)$. Women in Cd-Q4 had higher level of HbAlc (\%) than women in Cd-Q1 5.0 (4.6-5.3) vs. $4.8(4.5-5.1)(p<0.001)$, but no difference was observed for fasting blood glucose $(\mathrm{mmol} / \mathrm{L})$ $4.8(4.5-5.2)$ vs. $4.8(4.5-5.2)(p=0.92)$ nor for plasma insulin levels $6.0(4.0-9.0)$ vs. $6.0(4.0-8.0)(p=0.41)$.

No significant differences were found in history of previous chronic diseases or treatment of stroke, hypertension, goitre, cancer, inflammatory bowel disease, rheumatoid arthritis, asthma/chronic bronchitis, or kidney stones comparing women with fracture or non-vertebral osteoporotic fracture to those without fracture. More women with non-vertebral osteoporotic fractures had self-reported diabetes $(4.0 \%)$ compared to women without fracture $(2.2 \%)(p=0.017)$. More women with non-vertebral osteoporotic fracture $(10.9 \%)(p=0.028)$ and any fracture $(9.6 \%)(p=0.044)$ had been treated for gastric ulcer (found by X-ray or gastroscopy) compared to women without fracture (7.2\%). More women with non-vertebral osteoporotic fracture $(3.3 \%)(p=0.003)$ and any fracture $(2.4 \%)(p=0.038)$ had been treated for myocardial infarction compared to women without fracture (1.2\%). Self-reported diabetes and treatment of gastric ulcer were further evaluated using univariate Cox regression analysis (Table 2). Treatment for myocardial infarction was not included in the multivariate analysis as previous studies of this cohort have demonstrated an increase in cardiovascular disease with higher B-Cd levels [10].

In the univariate crude Cox regression, no significant association with fracture risk was observed with increasing levels 
Table 1 Descriptive data at baseline for all women and for women in quartiles 1-4

\begin{tabular}{|c|c|c|c|c|c|c|c|c|}
\hline & & & $\begin{array}{l}\text { All women } \\
n=2920 \\
\text { median }(25 \text { th }-75 \text { th } \\
\text { percentile) }\end{array}$ & $\begin{array}{l}\text { Quartile } 1 \\
n=730 \\
\text { median }(25 \text { th- }-75 \text { th } \\
\text { percentile) }\end{array}$ & $\begin{array}{l}\text { Quartile } 2 \\
n=730 \\
\text { median }(25 \text { th }-75 \text { th } \\
\text { percentile) }\end{array}$ & $\begin{array}{l}\text { Quartile } 3 \\
n=730 \\
\text { median }(25 \text { th }-75 \text { th } \\
\text { percentile) }\end{array}$ & $\begin{array}{l}\text { Quartile } 4 \\
n=730 \\
\text { median }(25 \text { th- } 75 \text { th } \\
\text { percentile) }\end{array}$ & $p$ value $^{\mathrm{a}}$ \\
\hline \multicolumn{2}{|c|}{ B-cadmium $(\mu \mathrm{g} / \mathrm{L})$} & $n=2920$ & $0.28(0.18-0.51)$ & $0.14(0.12-0.16)$ & $0.22(0.20-0.25)$ & $0.35(0.30-0.41)$ & $1.00(0.69-1.49)$ & \\
\hline \multicolumn{2}{|l|}{ Age (years) } & $n=2920$ & $58.0(52.0-63.0)$ & $57.0(52.0-62.0)$ & $59.0(53.0-63.0)$ & $59.0(54.0-63.0)$ & $56.0(52.0-62.0)$ & $p=0.14$ \\
\hline \multicolumn{2}{|l|}{ Height (cm) } & $n=2919$ & $\begin{array}{l}163.0 \\
\quad(159.0-168.0)\end{array}$ & $\begin{array}{l}163.0 \\
\quad(159.0-168.0)\end{array}$ & $\begin{array}{l}163.0 \\
\quad(159.0-167.0)\end{array}$ & $\begin{array}{l}164.0 \\
\quad(160.0-168.0)\end{array}$ & $\begin{array}{l}164.0 \\
\quad(160.0-168.0)\end{array}$ & $p=0.18$ \\
\hline \multicolumn{2}{|l|}{ Weight (kg) } & $n=2919$ & $66.0(60.0-74.0)$ & $67.0(60.0-75.0)$ & $66.0(59.0-74.0)$ & $67.0(62.0-74.0)$ & $65.0(58.0-73.0)$ & $p=0.002$ \\
\hline \multicolumn{2}{|c|}{$\begin{array}{l}\text { Body mass index } \\
\text { (BMI) }\left(\mathrm{kg} / \mathrm{m}^{2}\right)\end{array}$} & $n=2919$ & $24.6(22.5-27.6)$ & $24.7(22.7-28.0)$ & $24.5(22.5-27.5)$ & $24.9(22.8-27.8)$ & $24.3(21.7-27.1)$ & $p<0.001$ \\
\hline \multicolumn{2}{|c|}{$\begin{array}{l}\text { C-reactive protein } \\
\quad(\mathrm{CRP})(\mathrm{mg} / \mathrm{L})\end{array}$} & $n=2785$ & $1.30(0.70-2.80)$ & $1.3(0.7-2.8)$ & $1.2(0.6-2.4)$ & $1.3(0.7-2.6)$ & $1.5(0.7-3.4)$ & $p=0.09$ \\
\hline \multicolumn{2}{|c|}{$\begin{array}{l}\text { Age at menarche } \\
\text { (years) }\end{array}$} & $n=2829$ & $14.0(13.0-15.0)$ & $14.0(13.0-15.0)$ & $14.0(13.0-14.0)$ & $14.0(13.0-14.0)$ & $14.0(13.0-15.0)$ & $p=0.51$ \\
\hline \multicolumn{2}{|c|}{ Parity } & $n=2749$ & $2.0(1.0-2.0)$ & $2.0(1.0-2.0)$ & $2.0(1.0-2.0)$ & $2.0(1.0-2.0)$ & $2.0(1.0-3.0)$ & $p=0.06$ \\
\hline \multicolumn{2}{|c|}{ Lactation (months) } & $n=2298$ & $7.0(4.0-12.0)$ & $8.0(4.0-12.0)$ & $8.0(4.0-12.0)$ & $8.0(4.0-12.0)$ & $6.0(3.0-12.0)$ & $p=0.07$ \\
\hline \multirow{2}{*}{\multicolumn{2}{|c|}{$\begin{array}{l}\text { Age at menopause } \\
\text { (years) }\end{array}$}} & $n=2069$ & $50.0(47.0-52.0)$ & $50.0(48.0-53.0)$ & $50.0(47.0-52.0)$ & $50.0(47.0-53.0)$ & $50.0(46.0-52.0)$ & $p<0.001$ \\
\hline & & & $n(\%)$ & $n(\%)$ & $n(\%)$ & $n(\%)$ & $n(\%)$ & \\
\hline Married & (yes) & $n=2851$ & $1835(62.8)$ & $486(66.6)$ & $507(69.5)$ & $470(64.4)$ & $372(51.0)$ & $p<0.001$ \\
\hline Cohabiting & (no) & $n=2851$ & $771(26.4)$ & $182(24.9)$ & $165(22.6)$ & $177(24.2)$ & $247(33.8)$ & $p<0.001$ \\
\hline \multirow[t]{3}{*}{ Smoking } & (current) & $n=2850$ & $731(25.0)$ & $24(3.3)$ & $31(4.2)$ & $104(14.2)$ & $572(78.4)$ & $p<0.001$ \\
\hline & (previous) & & $781(26.7)$ & $206(28.2)$ & $232(31.8)$ & $265(36.3)$ & $78(10.7)$ & \\
\hline & (never) & & $1338(45.8)$ & $490(67.1)$ & 452 (61.9) & $340(46.6)$ & $56(7.7)$ & \\
\hline \multirow[t]{3}{*}{ Alcohol } & no current & $n=2844$ & $357(12.2)$ & $74(10.1)$ & $98(13.4)$ & $84(11.5)$ & $101(13.8)$ & \\
\hline & $<15$ g/day & & $2116(72.5)$ & $559(76.6)$ & $533(73.0)$ & $538(73.7)$ & 486 (66.6) & \\
\hline & $>15 \mathrm{~g} /$ day & & $371(12.7)$ & $86(11.8)$ & $83(11.4)$ & $85(11.6)$ & $117(16.0)$ & $p=0.001$ \\
\hline
\end{tabular}

Statistically significant $p$-values in italics

${ }^{\mathrm{a}} p$ value $\mathrm{Q} 1$ vs. Q4

of B-Cd but increasing age, self-reported diabetes, and gastric ulcer (Table 2). In the multivariate-adjusted Cox regression, independent predictors for increased fracture risk were gastric ulcer and age whereas increasing BMI decreased fracture risk (Table 2). The risk of first non-vertebral osteoporotic fractures was similarly not affected by increasing levels of B-Cd at baseline: HR 1.02 (95\% CI 0.82-1.27) when comparing CdQ4 vs. Cd-Q1. Analysing never and ever smokers separately regarding any fracture did not affect the results: HR $1.09(95 \%$ CI 0.68-1.73) for never smokers and HR 1.08 (95\% CI 0.831.39) for ever smokers comparing Cd-Q4 vs. Cd-Q1.

In total, 403 women died during follow-up. More women in Q4 died compared to Q1, 21.0 vs. $11.2 \%(p=<0.001)$. In the multivariate-adjusted Cox regression model, increasing age and BMI, current smoking, and diabetes were independent factors for increased mortality (Table 2). When analysing never and ever smokers separately regarding overall mortality, a HR of 1.10 (95\% CI 0.50-2.42) for never smokers and a HR 2.23 (95\% CI 1.44-3.44) for ever smokers were observed comparing Cd-Q4 vs. Cd-Q1.

Some women $n=95(3.3 \%)$ had had prevalent fractures, i.e. fractures before inclusion in the study. There was no difference in the number of women with prevalent fracture in Cd-Q1 vs. Cd-Q4 ( $n=28$ vs. $n=24 ; p=0.57$ ). Cox regression analyses for risk of fracture Cd-Q4 vs. Cd-Q1 during follow-up excluding women with prevalent fractures were similar: HR 1.07 (95\% CI 0.90-1.29) compared to analysis for all women. Hence, analyses were performed including women having had a fracture before inclusion in the study.

Use of hormone replacement therapy (HRT) occurred at baseline in 500 women out of 2536 women responding to the question. No difference in HRT users was observed for Cd-Q1 (18.9\%) vs. Cd-Q4 (16.2\%); $(p=0.08)$. The use of HRT decreased fracture risk during follow-up in the univariate analyses, HR 0.70 (95\% CI 0.58-0.84), as well as mortality, HR 0.75 (95\% CI 0.56-0.99). When added to the multivariate analysis, it did not affect the risk of $\mathrm{B}-\mathrm{Cd}$ on fracture risk for Cd-Q4 compared to Cd-Q1, HR 1.04 (95\% CI 0.79-1.37), but remained significant itself, HR 0.75 (95\% CI 0.61-0.92). Regarding mortality in the multivariate analysis, the use of HRT was not associated to decreased risk of mortality during follow-up, HR 0.89 (95\% CI 0.64-1.22), but B-Cd in Cd-Q4 compared to Cd-Q1 was no longer significantly associated to mortality, HR 1.43 (0.93-2.21). 
Table 2 Uni- and multivariate Cox regression analysis for fractures and death

\begin{tabular}{|c|c|c|c|c|c|c|c|c|c|}
\hline & & \multicolumn{4}{|c|}{ Fracture (yes/no) } & \multicolumn{4}{|c|}{ Death (yes/no) } \\
\hline & & \multicolumn{2}{|c|}{ Univariate } & \multicolumn{2}{|c|}{ Multivariate $^{\mathrm{b}}$} & \multicolumn{2}{|c|}{ Univariate } & \multicolumn{2}{|c|}{ Multivariate $^{\mathrm{b}}$} \\
\hline & & $n$ & $\operatorname{HR}(95 \% \mathrm{CI})^{\mathrm{a}}$ & $n$ & $\operatorname{HR}(95 \% \mathrm{CI})^{\mathrm{a}}$ & $n$ & $\operatorname{HR}(95 \% \mathrm{CI})^{1}$ & $n$ & $\operatorname{HR}(95 \% \mathrm{CI})^{\mathrm{a}}$ \\
\hline \multirow[t]{4}{*}{ Cadmium level } & Quartile 1 & 730 & 1.0 & 551 & 1.0 & 730 & 1.0 & 551 & 1.0 \\
\hline & Quartile 2 & 730 & $1.05(0.88-1.25)$ & 573 & $1.06(0.87-1.30)$ & 730 & $1.06(0.78-1.43)$ & 573 & $0.89(0.63-1.27)$ \\
\hline & Quartile 3 & 730 & $1.03(0.87-1.23)$ & 596 & $1.02(0.83-1.26)$ & 730 & $1.03(0.76-1.40)$ & 596 & $0.75(0.52-1.08)$ \\
\hline & Quartile 4 & 730 & $1.06(0.89-1.27)$ & 598 & $1.06(0.81-1.40)$ & 730 & $2.06(1.57-2.69)$ & 598 & $1.52(0.99-2.33)$ \\
\hline \multirow[t]{3}{*}{ Smoking status } & Never & 1338 & 1.0 & 1061 & 1.0 & 1338 & 1.0 & 1061 & 1.0 \\
\hline & Previous & 781 & $0.99(0.85-1.15)$ & 646 & $1.08(0.91-1.28)$ & 781 & $1.04(0.80-1.35)$ & 646 & $1.12(0.83-1.51)$ \\
\hline & Current & 731 & $0.99(0.85-1.16)$ & 611 & $1.08(0.84-1.40)$ & 731 & $1.84(1.47-2.32)$ & 611 & $1.65(1.11-2.45)$ \\
\hline \multirow[t]{2}{*}{ Age (years) } & & & 1.0 & & 1.0 & & 1.0 & & 1.0 \\
\hline & Continuous & 2920 & $1.04(1.03-1.05)$ & & $1.05(1.04-1.06)$ & 2872 & $1.11(1.09-1.13)$ & & $1.12(1.09-1.14)$ \\
\hline \multirow[t]{2}{*}{ Body mass index (BMI) $\left(\mathrm{kg} / \mathrm{m}^{2}\right)$} & & & 1.0 & & 1.0 & & 1.0 & & 1.0 \\
\hline & Continuous & 2919 & $0.99(0.98-1.01)$ & & $0.98(0.96-0.99)$ & 2871 & $1.04(1.02-1.06)$ & & $1.03(1.00-1.05)$ \\
\hline \multirow[t]{2}{*}{ Treatment for diabetes mellitus } & No & 2267 & 1.0 & 2264 & 1.0 & 2267 & 1.0 & 2264 & 1.0 \\
\hline & Yes & 57 & $1.52(1.01-2.28)$ & 54 & $1.40(0.91-2.14)$ & 57 & $2.76(1.67-4.57)$ & 54 & $2.05(1.21-3.48)$ \\
\hline \multirow[t]{2}{*}{ Treatment for gastric ulcer } & No & 2156 & 1.0 & 2153 & 1.0 & 2156 & 1.0 & 2153 & 1.0 \\
\hline & Yes & 186 & $1.35(1.07-1.71)$ & 165 & $1.35(1.05-1.74)$ & 189 & $1.69(1.19-2.39)$ & 165 & $1.29(0.89-1.87)$ \\
\hline
\end{tabular}

${ }^{a}$ Hazard ratio (HR) and $95 \%$ confidence interval (CI). Statistically significant ratios in italics

${ }^{\mathrm{b}}$ Cox regression analysis performed multivariate including cadmium level, smoking status, age, body mass index (BMI) $\left(\mathrm{kg} / \mathrm{m}^{2}\right)$, treatment for diabetes mellitus, and gastric ulcer

Kaplan-Meier curves for fracture (Fig. 1a) and allcause mortality (Fig. 1b) are shown (Fig. 1). Since high $\mathrm{Cd}$ was associated with increased mortality, which potentially could reduce the relationship between $\mathrm{Cd}$ and fractures at older age, a competing risk analysis, with mortality from any cause as the competing event, was performed. The competing risk analysis did not observe an increased fracture risk for $\mathrm{B}-\mathrm{Cd}$ as a univariate variable (Cd-Q1 as HR 1.0) sub-distribution hazard ratio (SHR) for Cd-Q4 0.97 (0.81-1.16). a) Fractures in Q1-Q4

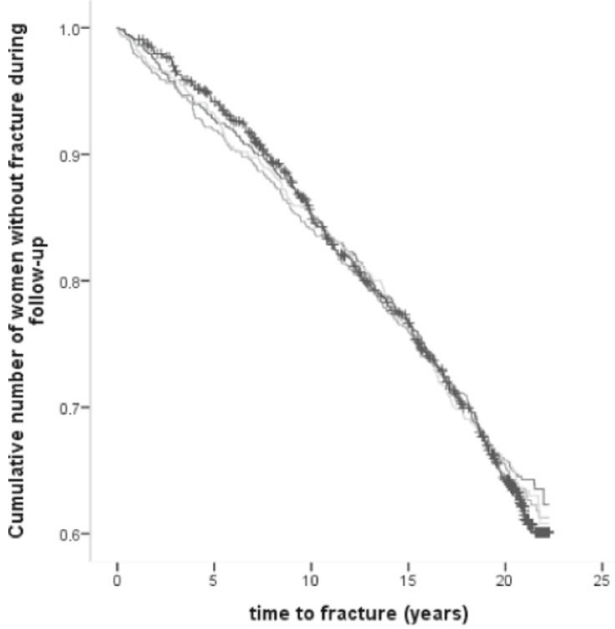

b) Deaths in Q1-Q4

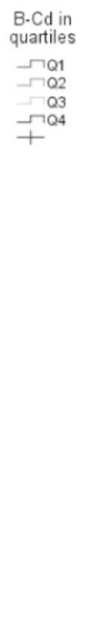

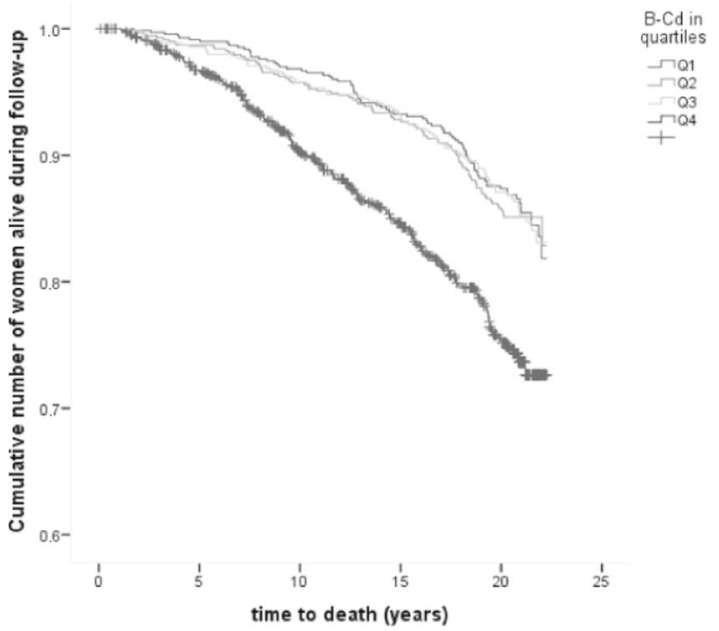

Fig. 1 a Kaplan-Meier graph for Q1-4 and cumulative percentage of women without fracture and time to fracture endpoint (ticks are censored cases). b Kaplan-Meier graph for Q1-4 and cumulative percentage of women alive and time to total endpoint (ticks are censored cases) 


\section{Discussion}

This study found no increased fracture risk associated with increasing levels of B-Cd but increased risk of overall mortality. Most studies on cadmium exposure, BMD, and fracture risk considered the relationship between urinary cadmium (UCd) and not blood cadmium as analysed in this study. The concentration of B-Cd reflects mostly recent exposure but also long-term exposure whereas U-Cd is a measure of total body burden of Cd reflecting the long-term exposure [1]. The follow-up time for fracture in this study was long, approximately 20 years, and it is possible that $\mathrm{B}-\mathrm{Cd}$ at baseline did not reflect long-term cadmium exposure.

Few previous studies have investigated B-Cd levels and fracture risk. In a case-control study, Sommar et al. observed no increased risk of hip fracture risk associated with increasing erythrocyte-CD adjusting for smoking, BMI, and height [19]. However, in a separate analysis for women, there was an increased risk of fracture (adjusted for smoking, BMI, height, and hormone replacement therapy) with OR 3.33 (95\% CI 1.29-8.56) [19]. Alfvén et al. found an inverse association between BMD and B-Cd levels in participants over 60 years [5]. Subjects with high cadmium levels had three times increased risk of low BMD (OR 2.9 (95\% CI 1.4-5.8)) compared to those with low cadmium levels [5].

Several studies found an association between increasing $\mathrm{Cd}$ levels and decreasing BMD and increased fracture risk [4]. A recent meta-analysis revealed an increased pooled relative risk of any fracture with increasing cadmium levels, relative risk 1.30 (95\% CI 1.13-1.49), but also concluded that the result should be interpreted cautiously due to heterogeneity of studies and risk of publication bias [20].

The impact of cadmium on bone metabolism has been debated and three main theories exist: [1] inhibited renal activation of vitamin D, [2] decreased absorption of calcium in the intestines due to competing action of cadmium, and [3] direct effects of $\mathrm{Cd}$ on collagen metabolism affecting bone structure [1]. There is also a more recent study indicating a direct effect of cadmium on bone cells [21].

In a review, Åkesson et al. found support for the hypothesis that cadmium is associated with decreased BMD and an increased fracture risk would occur at U-Cd as low as $0.5-2 \mu \mathrm{g} /$ $\mathrm{g}$ creatinine which is equivalent to $\mathrm{B}-\mathrm{Cd}$ levels of approximately $0.5-2 \mu \mathrm{g} / \mathrm{L}$ [4]. The median level of B-Cd in all women in this study was $0.28(0.18-0.51) \mu \mathrm{g} / \mathrm{L}$ and in the highest quartile (Cd-Q4) the level was $1.00(0.69-$ 1.49) $\mu \mathrm{g} / \mathrm{L}$; hence, women in Cd-Q4 are well in the B-Cd range where cadmium could be associated with BMD and fracture risk. BMD was not measured in this study, but in another study based on the MDC cohort, BMD was measured and an inverse correlation between BMD and B-Cd was found. However, the results did not remain significant when adjusted for smoking [22].
This study investigates first incident fractures and in order to avoid underestimation of osteoporotic fracture risk, the risk of the first non-vertebral osteoporotic fracture has also been investigated if occurring after a non-osteoporotic first fracture. Engström et al. did not observe an increased overall first fracture risk in all women HR 1.16 (95\% CI 0.89-1.50) when comparing higher levels of U-Cd with lower levels of U-Cd, but when including only never smokers, the risk was increased HR 2.03 (95\% CI 1.33-3.09) [7]. In the present study, no difference was observed comparing never smokers with ever smokers in regard to fracture risk associated with increased BCd levels.

Increased mortality was observed in women with high B$\mathrm{Cd}$ levels at baseline even after adjustment for smoking which is in agreement with previous reports [23, 24]. Hence, if more women in Cd-Q4 died during follow-up, this could result in fewer fractures in Cd-Q4, but the survival analysis using Cox regression considered this, since those who died became censored. The competing risk analysis also verifies the results. A recent review of all-cause mortality found that levels of U-Cd was associated with increased mortality HR 1.44 (95\% CI $1.25-1.64)$ when comparing the highest category with the lowest [25]. A study based on B-Cd found a HR 1.50 (95\% CI 1.07-1.20) [23] for mortality with increasing B-Cd levels. An association between cadmium exposure and cardiovascular mortality has been investigated in this cohort previously where increasing levels of cadmium was associated with development of atherosclerotic plaques in the carotid artery [12] and cardiovascular disease [10].

Diabetes has been studied previously in regard to fracture risk and both type 1 diabetes mellitus [26] and type 2 diabetes mellitus [27] are associated with increased fracture risk. Our results agree with this, as women with diabetes showed an increased risk of fracture. In the present study, women with a history of gastric ulcer had an increased fracture risk HR 1.33 (95\% CI 1.02-1.75) in the multivariate analysis. These findings strengthen our recent results in another study of postmenopausal women aged 50-64 years where we found an increased risk of fracture in women using proton pump inhibitors (PPI) with OR 2.53 (95\% CI 1.28-4.99) [28]. In line with the vast majority of observational studies on HRT, statistically significant reductions by HRT were found on overall mortality and fracture incidence $[29,30]$.

The results of this study are substantiated by a long followup period and fracture data from national registries. The relatively large number of included women is also a strength of the study. Limitations include the fact that smoking habits and history of diseases other than fractures are self-reported based on questionnaires. The study has investigated the association between B-Cd and fracture in women only, and hence, the results are limited to women only. Even though women in Cd-Q4 consumed more alcohol daily, there was no observed association with increased fracture risk in this group and in 
this aspect, it would have been interesting to study the number of falls in this group of women. The number of falls is a wellknown risk factor for fracture. Unfortunately, there is no data regarding falls available.

In conclusion, high blood cadmium levels did not increase fracture risk, but doubled the overall mortality rate in middleaged women. Gastric ulcer disease was associated with increased fracture risk after adjustment for other risk factors in this group of women.

Acknowledgements LM has received time-limited grants from the Medical Faculty at Lund University and the Strategic Research Area EpiHealth and a travel grant from the Maggie Stephens' Foundation.

The authors thank Linda Johnson for her help with the competing risk analysis.

Compliance with ethical standards All participants provided written informed consent and the study was approved by the Lund University Ethics Committee (MDC LU 51-90) and for the cadmium sub-study (2009/633). The current study was also approved by the steering committee of the MDC study (2015-011). Data retrieval from the separate outpatient data registry covering the years 1992-2001 were granted by the Deputy Chief Health Officer (Region Skåne; decision number 236-16).

\section{Conflicts of interest None.}

Open Access This article is distributed under the terms of the Creative Commons Attribution-NonCommercial 4.0 International License (http:// creativecommons.org/licenses/by-nc/4.0/), which permits any noncommercial use, distribution, and reproduction in any medium, provided you give appropriate credit to the original author(s) and the source, provide a link to the Creative Commons license, and indicate if changes were made.

\section{References}

1. Nordberg GF, Nogawa K, Nordberg M (2015) Chapter 32 - cadmium. Handbook on the toxicology of metals (fourth edition). Academic Press, San Diego, pp 667-716

2. James KA, Meliker JR (2013) Environmental cadmium exposure and osteoporosis: a review. Int J Public Health 58(5):737-745

3. Youness ER, Mohammed NA, Morsy FA (2012) Cadmium impact and osteoporosis: mechanism of action. Toxicol Mech Methods 22(7):560-567

4. Åkesson A, Barregard L, Bergdahl IA, Nordberg GF, Nordberg M, Skerfving S (2014) Non-renal effects and the risk assessment of environmental cadmium exposure. Environ Health Perspect 122(5):431-438

5. Alfvén T, Elinder CG, Hellström L, Lagarde F, Järup L (2004) Cadmium exposure and distal forearm fractures. J Bone Miner Res Off J Am Soc Bone Miner Res 19(6):900-905

6. Järup L, Alfvén T (2004) Low level cadmium exposure, renal and bone effects - the OSCAR study. Biometals 17(5):505-509

7. Engström A, Michaëlsson K, Suwazono Y, Wolk A, Vahter M, Akesson A (2011) Long-term cadmium exposure and the association with bone mineral density and fractures in a population-based study among women. J Bone Miner Res Off J Am Soc Bone Miner Res 26(3):486-495
8. Wallin M, Barregard L, Sallsten G, Lundh T, Karlsson MK, Lorentzon $\mathrm{M}$ et al (2016) Low-level cadmium exposure is associated with decreased bone mineral density and increased risk of incident fractures in elderly men: the MrOS Sweden study. J Bone Miner Res Off J Am Soc Bone Miner Res 31(4):732-741

9. Akesson A, Bjellerup P, Lundh T, Lidfeldt J, Nerbrand C, Samsioe $\mathrm{G}$ et al (2006) Cadmium-induced effects on bone in a populationbased study of women. Environ Health Perspect 114(6):830-834

10. Barregard L, Sallsten G, Fagerberg B, Borné Y, Persson M, Hedblad B et al (2016) Blood cadmium levels and incident cardiovascular events during follow-up in a population-based cohort of Swedish adults: the Malmö Diet and Cancer Study. Environ Health Perspect 124(5):594-600

11. Borné Y, Barregard L, Persson M, Hedblad B, Fagerberg B, Engström G (2015) Cadmium exposure and incidence of heart failure and atrial fibrillation: a population-based prospective cohort study. BMJ Open 5(6):e007366

12. Fagerberg B, Barregard L, Sallsten G, Forsgard N, Ostling G, Persson $\mathrm{M}$ et al (2015) Cadmium exposure and atherosclerotic carotid plaques - results from the Malmö diet and Cancer study. Environ Res 136:67-74

13. Berglund G, Elmstähl S, Janzon L, Larsson SA (1993) The Malmo Diet and Cancer Study. Design and feasibility. J Intern Med 233(1): 45-51

14. Rosvall M, Persson M, Östling G, Nilsson PM, Melander O, Hedblad B et al (2015) Risk factors for the progression of carotid intima-media thickness over a 16-year follow-up period: the Malmö Diet and Cancer Study. Atherosclerosis 239(2):615-621

15. Engström G, Gerhardsson de Verdier M, Rollof J, Nilsson PM, Lohmander LS (2009) C-reactive protein, metabolic syndrome and incidence of severe hip and knee osteoarthritis. A populationbased cohort study. Osteoarthr Cartil 17(2):168-173

16. Borné Y, Fagerberg B, Persson M, Sallsten G, Forsgard N, Hedblad $B$ et al (2014) Cadmium exposure and incidence of diabetes mellitus - results from the Malmö Diet and Cancer study. PLoS One 9(11):e112277

17. Cunningham TD, Martin BC, DeShields SC, Romero CC (2016) The impact of osteoporotic fractures compared with other health conditions in older adults living in Virginia, United States. Osteoporosis international: a journal established as result of cooperation between the European Foundation for Osteoporosis and the National Osteoporosis Foundation of the USA 27(10):2979-2988

18. Schousboe JT (2016) Epidemiology of vertebral fractures. Journal of clinical densitometry : the official journal of the International Society for Clinical Densitometry 19(1):8-22

19. Sommar JN, Pettersson-Kymmer U, Lundh T, Svensson O, Hallmans G, Bergdahl IA (2014) Hip fracture risk and cadmium in erythrocytes: a nested case-control study with prospectively collected samples. Calcif Tissue Int 94(2):183-190

20. Cheng X, Niu Y, Ding Q, Yin X, Huang G, Peng J et al (2016) Cadmium exposure and risk of any fracture: a PRISMA-compliant systematic review and meta-analysis. Medicine (Baltimore) 95(10): e2932

21. Bhattacharyya MH (2009) Cadmium osteotoxicity in experimental animals: mechanisms and relationship to human exposures. Toxicol Appl Pharmacol 238(3):258-265

22. Rignell-Hydbom A, Skerfving S, Lundh T, Lindh CH, Elmståhl S, Bjellerup P et al (2009) Exposure to cadmium and persistent organochlorine pollutants and its association with bone mineral density and markers of bone metabolism on postmenopausal women. Environ Res 109(8):991-996

23. Tellez-Plaza M, Navas-Acien A, Menke A, Crainiceanu CM, Pastor-Barriuso R, Guallar E (2012) Cadmium exposure and all- 
cause and cardiovascular mortality in the U.S. general population. Environ Health Perspect 120(7):1017-1022

24. Menke A, Muntner P, Silbergeld EK, Platz EA, Guallar E (2009) Cadmium levels in urine and mortality among U.S. adults. Environ Health Perspect 117(2):190-196

25. Larsson SC, Wolk A (2015) Urinary cadmium and mortality from all causes, cancer and cardiovascular disease in the general population: systematic review and meta-analysis of cohort studies. Int $\mathrm{J}$ Epidemiol

26. Hough FS, Pierroz DD, Cooper C, Ferrari SL, Group ICBaDW (2016) Mechanisms in endocrinology: mechanisms and evaluation of bone fragility in type 1 diabetes mellitus. European journal of endocrinology/European Federation of Endocrine Societies 174(4): R127-R138
27. Schwartz AV (2016) Epidemiology of fractures in type 2 diabetes. Bone 82:2-8

28. Moberg LM, Nilsson PM, Samsioe G, Borgfeldt C (2014) Use of proton pump inhibitors (PPI) and history of earlier fracture are independent risk factors for fracture in postmenopausal women. The WHILA study Maturitas 78(4):310-315

29. Salpeter SR, Walsh JM, Greyber E, Ormiston TM, Salpeter EE (2004) Mortality associated with hormone replacement therapy in younger and older women: a meta-analysis. J Gen Intern Med 19(7):791-804

30. Rossouw JE, Anderson GL, Prentice RL, LaCroix AZ, Kooperberg C, Stefanick ML et al (2002) Risks and benefits of estrogen plus progestin in healthy postmenopausal women: principal results from the Women's Health Initiative randomized controlled trial. JAMA 288(3):321-333 